\title{
Penerapan Metode EOQ dalam Pengendalian Bahan Baku Guna Efisiensi Total Biaya Persediaan Bahan Baku
}

\author{
Sri Hastari*, A. Ratna Pudyaningsih, Paring Wahyudi \\ Program Studi Manajemen, Fakultas Ekonomi, Universitas Merdeka Pasuruan, \\ Pasuruan, Indonesia \\ *sri.hastari@gmail.com
}

\begin{abstract}
The purpose of this study is to facilitate SMEs who are members of the WASUKA cooperative in carrying out raw material inventory control to be more effective and efficient using the Economic Order Quantity (EOQ) method. This research is a descriptive analytic research type that aims to describe or provide an overview of the research object through the collected data. This study uses two data sources, namely primary data in the form of data regarding the purchase and use of raw materials and the number of order costs and storage costs. Meanwhile, other data sources are secondary data, namely data on company history, organizational structure, and other supporting data. In this study, the data collection techniques used are observation, interviews, and literature study. This research shows that the purchase of raw materials for wheat flour and peeled green beans by several SMEs in Pia Gempol village when using the EOQ method with several qualifications determined is considered quite efficient. However, the percentage is not too large. This condition may be due to the frequency of purchases made quite often so that the order cost and storage cost is also relatively high. Besides, the raw materials needed by several SMEs that are members of the WASUKA cooperative is considered relatively easy to obtain, considering the existence of suppliers of these raw materials close to the business location.
\end{abstract}

Keywords: EOQ, Inventory, Raw Materials, SMEs

\section{PENDAHULUAN}

Setiap pelaku bisnis ingin mendapatkan manfaat dan keuntungan dalam menjalankan usahanya. Salah satu upaya yang dapat digunakan yaitu memaksimalkan segenap sumber daya yang dimiliki oleh perusahaan dengan sebaik-baiknya agar tecipta suatu produk yang berkualitas dan memiliki daya saing yang tinggi. Untuk mencapai tujuan agar produk yang dihasilkan sesuai dengan yang direncanakan maka keputusan-keputusan penting dan tepat perlu dilakukan.
Perencanaan dan pengendalian bahan baku sangat penting dilakukan oleh semua pelaku usaha karena dapat meminimalisir biaya-biaya dan meningkatkan laba perusahaan. Beberapa kendala yang sering terjadi ketika melakukan kegiatan perencanaan dan pengendalian adalah bagaimana perusahaan dengan tepat menyediakan bahan baku dengan kuantitas yang diperlukan sehingga tidak menganggu proses produksi dan modal yang tertanam dalam persediaan bahan baku tidak berlebih. Masalah tersebut akan mempunyai pengaruh 
terhadap penentuan beberapa hal: 1) Berapa kuantitas yang akan dibeli dalam periode akuntansi tertentu, 2) Berapa jumlah atau kuantitas yang akan dibeli dalam setiap kali dilakukan pembelian, 3) Kapan pemesanan bahan dilakukan, 4) Berapa jumlah minimum kuantitas bahan yang harus selalu ada dalam persediaan pengamanan (safety stock) agar perusahaan dapat terhindar dari kemungkinan kemacetan produksi akibat keterlambatan bahan, dan 5) Berapa jumlah maksimum kuantitas bahan dalam persediaam agar dana yang ditahan tidak berlebihan (Lovelock \& Wirtz, 2014).

Model Economic Order Quantity (EOQ) adalah salah satu teknik pengendalian persediaan yang paling sering digunakan. Teknik ini relatif mudah akan tetapi didasarkan pada beberapa asumsi: 1) Jumlah permintaan diketahui, cukup konstan dan independen, 2) Waktu antara pemesanan dan penerimaan pesanan (waktu tunggu) telah diketahui dan bersifat konstan, 3) Persediaan segera diterima dan selesai seluruhnya, dengan kata lain persediaan yang di pesan tiba dalam satu kelompok pada suatu waktu, 4) Tidak tersedia diskon kuantitas, 5) Biaya variabel hanya biaya untuk memesan dan biaya untuk menyimpan persediaan dalam waktu tertentu, dan 6) Kehabisan atau kekurangan persediaan dapat dihindari jika pemesanan dilakukan pada waktu yang tepat (Heizer, 2016).

Salah satu jenis usaha yang tergabung dalam Koperasi Waru Sukses Berkarya (Wasuka) adalah UKM yang bergerak dibidang industri makanan yang kegiatan utamanya memproduksi pia yang berbahan dasar tepung terigu dan kacang hijau kupas. Penerimaan bahan baku tepung terigu dan kacang hijau kupas tersebut berasal dari para suplier. Bahan baku tersebut harus selalu tersedia untuk menunjang kelancaran proses produksi. Oleh sebab itu, perlu dilaksanakan pengendalian persediaan bahan baku. Suatu usaha harus bisa mengelola persediaan dengan baik agar dapat memiliki persediaan yang optimal demi kelancaran operasi. Namun berdasarkan observasi awal, keadaan para pelaku UKM produsen pia ini dalam menyediakan bahan baku tepung terigu maupun kacang hijau kupas tidak terjadwal. Apabila bahan baku di gudang mereka menipis, mereka baru akan melakukan pembelian bahan baku. Hal ini lambat laun akan berakibat terhadap dana operasional apabila terjadi kekurangan dana dalam melakukan pembelian yang tentunya akan berpengaruh terhadap kelancaran proses produksi.

Berdasar uraian di atas penelitian yang dilakukan di Kampung Pia ini, bertujuan untuk : 1) Mengetahui besarnya pesanan persediaan bahan baku paling ekonomis (EOQ), 2) Mengetahui berapa banyak frekuensi dalam satu periode pembelian bahan baku yang harus dilakukan, 3) Mengetahui berapa besarnya persediaan pengaman (Safety Stocks) yang harus disiapkan, 4) Mengetahui berapa batas pemesanan bahan baku selama masa tenggang (Reorder Point), 5) Mengetahui berapa total biaya persediaan bahan baku, dan 6) Mengetahui tingkat efisiensi total biaya yang dikeluarkan dalam membeli bahan baku .

\section{METODE}

Penelitian yang dilakukan ini termasuk dalam jenis penelitian deskripstif analitik yang bertujuan untuk mendeskripsikan atau memberikan gambaran terhadap objek yang diteliti melalui data yang telah terkumpul sebagaimana adanya (Sugiyono,2011).

Penelitian menggunakan data primer berupa data mengenai pembelian dan penggunaan bahan baku serta besarnya biaya pesan dan biaya simpan. Sedangkan teknik pengumpulan data yang digunakan yaitu observasi, wawancara dan studi pustaka. Obyek penelitian adalah UKM yang berada di Kampung Pia Gempol Kabupaten Pasuruan sejumlah 20 UKM.

Langkah pertama dalam penentuan pembelian ekonomis yaitu menentukan kebutuhan bahan baku pada periode 2019 dengan menggunakan metode Moving Average atau rata-rata bergerak 3 tahunan. dikarenakan metode tersebut dinilai cocok 
dengan kondisi UKM yang tergabung dalam Koperasi Waru Sukses Berkarya yang memiliki catatan penggunaan bahan baku yang relatif stabil atau tidak berfluktuasi. Adapun penentuan kebutuhan bahan baku pada tahun 2019 menggunakan rumus:

$\mathrm{F}_{\mathrm{t}}=\frac{\text { Epermintaan periodesebelumnya }}{n}$

Langkah kedua yaitu penentuan pembelian ekonomis $(E O Q)$, frekuensi pembelian dan pembelian optimal dapat menggunakan rumus :

$E O Q=\sqrt{\frac{2 . \mathrm{S} . \mathrm{D}}{\mathrm{H}}}$

$\mathrm{N}=\frac{\mathrm{D}}{\mathrm{Q}}$

$\mathrm{T}=\frac{\text { hari kerja (tahun] }}{N}$

Dimana:

EOQ $=$ jumlah pemesanan ekonomis

$\mathrm{S}=$ biaya setiap kali pemesanan

$\mathrm{D}=$ jumlah pembelian selama 1 periode

$\mathrm{H}=$ biaya penyimpanan

Setelah pembelian ekonomis telah ditentukan, selanjutnya menghitung jumlah persediaan pengaman digunakan metode statistik yaitu membandingkan rata-rata bahan baku dengan pemakaian bahan baku, kemudian dicari penyimpangannya. Pada umumnya para pelaku usaha menggunakan batas toleransi sebesar $5 \%$.

Langkah selanjutnya yaitu menetukan titik pemesanan ulang. Titik pemesanan ulang adalah keadaan dimana pelaku usaha pia harus melakukan pemesanan bahan bakunya kembali, dapat ditentukan menggunakan rumus:

$\mathrm{ROP}=$ lead time demand + safety stock

Titik pemesanan ulang diketahui, selanjutnya menentukan total biaya persediaan bahan baku yang dapat dilakukan dengan rumus matematis sebagai berikut :

$\mathrm{TC}=\frac{\mathrm{D}}{\mathrm{Q}} \mathrm{S}+\frac{\mathrm{Q}}{2} \mathrm{H}$
$\mathrm{Q}=$ jumlah pemesanan ekonomis

$\mathrm{S}=$ biaya setiap kali pemesanan

$\mathrm{D}=$ jumlah pembelian selama 1 periode

$\mathrm{H}=$ biaya penyimpanan

$\mathrm{TCC}=$ total biaya persediaan

$$
\text { Langkah terakhir yaitu }
$$

menghitung tingkat efisiensi persediaan bahan baku apabila menggunakan metode EOQ. Untuk mengetahui tingkat efisiensi persediaan bahan baku dapat menggunakan rumus :

anggaran sebelum - anggaran sesudah anggaran sebelum

\section{HASIL DAN PEMBAHASAN}

Dalam penelitian ini, UKM diklasifikasikan berdasarkan jumlah kebutuhan bahan baku. Untuk tepung terigu diklasifikasikan menjadi 3 klasifikasi, sedangkan untuk kebutuhan bahan baku kacang hijau kupas menjadi 4 klasifikasi. Hal ini karena kebutuhan untuk tepung terigu semua UKM tidak ada yang di bawah 1.000 kg per tahunnya. Data klasifikasi bahan baku disajikan pada Tabel 1 dan Tabel 2.

Tabel 1. Kebutuhan Bahan Baku Tepung Terigu

\begin{tabular}{lccc}
\hline \multirow{2}{*}{ UKM } & \multicolumn{3}{c}{ Tahun } \\
\cline { 2 - 4 } & 2016 & 2017 & 2018 \\
\hline Karomah & 5.072 & $5.095,4$ & $5.116,8$ \\
Khotijah & $3.387,2$ & $3.410,6$ & 3.432 \\
Mahen & $16.709,3$ & $16.754,7$ & $17.347,2$ \\
4sekawan & $3.387,2$ & $3.410,6$ & 3.432 \\
Aldy & $3.387,2$ & $3.410,6$ & 3.432 \\
Bejo Mulyo & $5.365,8$ & $5.589,8$ & 5.772 \\
Iloh Cindy & 5.072 & $5.095,4$ & $5.116,8$ \\
Berkah & $3.387,2$ & $3.410,6$ & 3.432 \\
Surya & $9.780,8$ & 9.817 & $10.202,4$ \\
Aqila & $6.256,8$ & $6.651,8$ & $6.801,6$ \\
\hline \multicolumn{1}{c}{ TOTAL } & $\mathbf{6 1 . 8 0 5 , 5}$ & $\mathbf{6 2 . 6 4 6 , 5}$ & $\mathbf{6 4 . 0 8 4 , 8}$ \\
\hline Amel & 2.260 & $2.313,3$ & $2.371,2$ \\
Umic & $2.700,2$ & $2.733,7$ & $2.714,4$ \\
Uyoy Rasa & 2.260 & $2.313,3$ & $2.371,2$ \\
\hline \multicolumn{1}{c}{ TOTAL } & $\mathbf{7 . 2 2 0 , 2}$ & $\mathbf{7 . 3 6 0 , 3}$ & $\mathbf{7 . 4 5 6 , 8}$ \\
\hline Puspita & $1.685,3$ & $1.691,2$ & 1.716 \\
Arum & $1.685,3$ & $1.691,2$ & 1.716 \\
Mandiri & $1.685,3$ & $1.691,2$ & 1.716 \\
Kharisma & $1.685,3$ & $1.691,2$ & 1.716 \\
Miya Jaya & $1.685,3$ & $1.691,2$ & 1.716 \\
Bunda & $1.685,3$ & $1.691,2$ & 1.716 \\
Kurnia & $1.303,9$ & $1.313,2$ & $1.372,8$ \\
\hline \multicolumn{1}{c}{ TOTAL } & $\mathbf{1 1 . 4 1 5 , 7}$ & $\mathbf{1 1 . 4 6 0 , 4}$ & $\mathbf{1 1 . 6 6 8 , 8}$ \\
\hline Sumber: & &
\end{tabular}

Sumber: data primer diolah penulis, 2019

Tabel 1 menjelaskan bahwa UKM yang termasuk dalam klasifikasi kebutuhan 
bahan baku tepung terigu $\geq 3.000 \mathrm{~kg}$ per tahun sebesar 10 UKM terdiri dari UKM Karomah, UKM Khotijah, UKM Mahen, UKM 4 Sekawan, UKM Aldy, UKM Bejo Mulyo, UKM Iloh Cindy, UKM Berkah, UKM Surya, dan UKM Aqila dengan kebutuhan bahan baku terbanyak adalah UKM Mahen di tahun 2018 sebesar 17.347,2 kg dan kebutuhan bahan baku paling sedikit oleh UKM Khotijah, UKM 4 Sekawan dan UKM Aldy di tahun 2016 sebesar $3.387,2 \mathrm{~kg}$ tepung terigu.

Klasifikasi bahan baku tepung terigu antara 2.000-2.999 kg per tahun sebesar 3 UKM terdiri dari UKM Amel, UKM Umic, dan UKM Uyoy Rasa dengan kebutuhan bahan baku terbanyak oleh UKM Umic sebesar $2.714,4 \mathrm{~kg}$ di tahun 2018 dan paling sedikit oleh UKM Amel dan UKM Uyoy Rasa sebesar $2.260 \mathrm{~kg}$ di tahun 2016.

Klasifikasi kebutuhan bahan baku tepung terigu yang terakhir antara 1.000 $1.999 \mathrm{~kg}$ per tahun sebesar 7 UKM terdiri dari UKM Puspita, UKM Arum, UKM Mandiri, UKM Kharisma, UKM Miya Jaya, UKM Bunda dan UKM Kurnia dengan ratarata kebutuhan bahan baku tepung terigu sama pada tiap UKM kecuali UKM Kurnia yang kebutuhan bahan baku tepung terigu paling sedikit yaitu 103,9 kg di tahun 2016.

Tabel 2. Kebutuhan Bahan Baku Kacang Hijau Kupas

\begin{tabular}{lccc}
\hline \multirow{2}{*}{ UKM } & \multicolumn{3}{c}{ Tahun } \\
\cline { 2 - 4 } & 2016 & 2017 & 2018 \\
\hline Mahen & $8.744,3$ & $9.073,2$ & $9.172,8$ \\
Surya & $4.968,7$ & $5.146,1$ & $5.491,2$ \\
Bejo Mulyo & 3.048 & 3.086 & 3.120 \\
Aqila & $3.312,4$ & $3.613,8$ & $3.681,6$ \\
\hline \multicolumn{1}{c}{ TOTAL } & $\mathbf{2 0 . 0 7 3 , 4}$ & $\mathbf{2 0 . 9 1 9 , 1}$ & $\mathbf{2 1 . 4 6 5 , 6}$ \\
\hline Karomah & $2.582,9$ & $2.651,4$ & $2.745,6$ \\
Iloh Cindy & $2.585,9$ & $2.651,4$ & $2.745,6$ \\
\hline \multicolumn{1}{c}{ TOTAL } & $\mathbf{5 . 1 6 5 , 8}$ & $\mathbf{5 . 3 0 2 , 8}$ & $\mathbf{5 . 4 9 1 , 2}$ \\
\hline Khotijah & $1.724,5$ & $1.733,4$ & $1.840,8$ \\
4sekawan & $1.724,5$ & $1.733,4$ & $1.840,8$ \\
Aldy & $1.724,5$ & $1.733,4$ & $1.840,8$ \\
Berkah & $1.724,5$ & $1.733,4$ & $1.840,8$ \\
Amel & $1.186,3$ & $1.234,8$ & $1.279,2$ \\
Umic & $1.224,8$ & $1.378,3$ & $1.466,4$ \\
Uyoy Rasa & $1.186,3$ & $1.234,8$ & $1.279,2$ \\
\hline \multicolumn{1}{c}{ TOTAL } & $\mathbf{1 0 . 4 9 5 , 4}$ & $\mathbf{1 0 . 7 8 1 , 5}$ & $\mathbf{1 1 . 3 8 8}$ \\
\hline Puspita & 831,7 & 867 & 904,8 \\
Arum & 831,7 & 867 & 904,8
\end{tabular}

\begin{tabular}{lccc}
\hline \multirow{2}{*}{ UKM } & \multicolumn{3}{c}{ Tahun } \\
\cline { 2 - 4 } & 2016 & 2017 & 2018 \\
\hline Mandiri & 831,7 & 867 & 904,8 \\
Kharisma & 831,7 & 867 & 904,8 \\
Miya Jaya & 831,7 & 867 & 904,8 \\
Bunda & 831,7 & 867 & 904,8 \\
Kurnia & 663,3 & 692,8 & 748,8 \\
\hline \multicolumn{1}{c}{ TOTAL } & $\mathbf{5 . 6 5 3 , 5}$ & $\mathbf{5 . 8 9 4 , 8}$ & $\mathbf{6 . 1 7 7 , 6}$ \\
\hline
\end{tabular}

Sumber: data primer diolah, 2019

Tabel 2 menjelaskan bahwa UKM yang termasuk dalam klasifikasi kebutuhan bahan baku kacang hijau kupas $\geq 3.000 \mathrm{~kg}$ per tahun sebesar 4 UKM terdiri dari UKM Mahen, UKM Bejo Mulyo, UKM Surya, dan UKM Aqila dengan kebutuhan bahan baku terbanyak adalah UKM Mahen di tahun 2018 sebesar $9.172,8 \mathrm{~kg}$ dan kebutuhan bahan baku paling sedikit oleh UKM Bejo Mulyo di tahun 2016 sebesar $3.048 \mathrm{~kg}$ tepung terigu.

Klasifikasi bahan baku kacang hijau kupas antara 2.000-2.999 kg per tahun sebesar 2 UKM terdiri dari UKM Kromah dan UKM Iloh Cindy dengan kebutuhan bahan baku yang sama sebesar 2.745,6 kg di tahun 2018 dan paling sedikit $2.582,9 \mathrm{~kg}$ di tahun 2016.

Klasifikasi kebutuhan bahan baku kacang hijau kupas antara 1.000-1.999 Kgper tahun sebesar 7 UKM terdiri dari UKM Khotijah, UKM 4 Sekawan, UKM Aldy, UKM Berkah, UKM Amel, UKM Umic dan UKM Uyoy Rasa dengan jumlah kebutuhan baku paling banyak dilakukan oleh UKM Khotijah, UKM 4 Sekawan, UKM Aldy, dan UKM Berkah sebesar $1.840,8 \mathrm{~kg}$ di tahun 2018 dan kebutuhan bahan baku paling sedikit oleh UKM Amel dan UKM Uyoy Rasa sebesar 1.186,3 kg di tahun 2016.

Klasifikasi kebutuhan bahan baku kacang hijau kupas $<1.000 \mathrm{~kg}$ sebesar 7 UKM terdiri dari UKM Puspita, UKM Arum, UKM Mandiri, UKM Kharisma, UKM Miya Jaya, UKM Bunda dan UKM Kurnia dengan rata-rata kebutuhan bahan baku kacang hijau kupas sam di tahun 2018 sebesar 904,8 kg kecuali UKM Kurnia dengan kebutuhan bahan baku paling sedikit 663,3 kg di tahun 2016. 
Klasifikasi kebutuhan bahan baku baik tepung terigu maupun kacang hijau kupas pada UKM disajikan pada Tabel 3.

Tabel 3. Klasifikasi UKM

\begin{tabular}{|c|c|c|c|c|}
\hline \multirow[b]{2}{*}{$\begin{array}{c}\text { Bahan } \\
\text { Baku }\end{array}$} & \multicolumn{4}{|c|}{ Klasifikasi } \\
\hline & $\begin{array}{l}\geq 3.000 \mathrm{~kg} \\
\text { per tahun }\end{array}$ & $\begin{array}{c}2.000- \\
2.999 \mathrm{~kg} \\
\text { per } \\
\text { tahun }\end{array}$ & $\begin{array}{c}1.000- \\
1.999 \mathrm{~kg} \\
\text { per tahun }\end{array}$ & $\begin{array}{c}<1.000 \\
\mathrm{~kg} \\
\text { per tahun }\end{array}$ \\
\hline \multirow{13}{*}{$\begin{array}{l}\text { Tepung } \\
\text { terigu }\end{array}$} & Karomah & Amel & Puspita & \\
\hline & Khotijah & Umic & Arum & \\
\hline & Mahen & Uyoy & Mandiri & \\
\hline & & Rasa & & \\
\hline & 4 sekawan & & Kharisma & \\
\hline & Aldy & & Miya & \\
\hline & & & Jaya & \\
\hline & Bejo & & Bunda & \\
\hline & Mulyo & & & \\
\hline & Iloh Cindy & & Kurnia & \\
\hline & Berkah & & & \\
\hline & Surya & & & \\
\hline & Aqila & & & \\
\hline \multirow{11}{*}{$\begin{array}{l}\text { Kacang } \\
\text { Hijau } \\
\text { Kupas }\end{array}$} & Mahen & Karomah & Khotijah & Puspita \\
\hline & Surya & Iloh & 4sekawan & Arum \\
\hline & & Cindy & & \\
\hline & Bejo & & Aldy & Mandiri \\
\hline & Mulyo & & & \\
\hline & Aqila & & Berkah & Kharisma \\
\hline & & & Amel & Miya \\
\hline & & & & Jaya \\
\hline & & & Umic & Bunda \\
\hline & & & Uyoy & Kurnia \\
\hline & & & Rasa & \\
\hline
\end{tabular}

Sumber: data primer diolah, 2019

\section{Biaya Pesan}

Biaya pesan terdiri atas biaya yang dikeluarkan dalam pemesanan bahan baku tepung terigu dan kacang hijau kupas yang dilakukan oleh beberapa UKM tersebut, diantaranya biaya telepon dan biaya pengiriman. Besar biaya pesan disajikan pada Tabel 4.

Tabel 4. Biaya Pesan

\begin{tabular}{cccc}
\hline Tahun & $\begin{array}{c}\text { Biaya telp } \\
(\mathrm{Rp})\end{array}$ & $\begin{array}{c}\text { Biaya } \\
\text { pengiriman } \\
(\mathrm{Rp})\end{array}$ & $\begin{array}{c}\text { Total } \\
(\mathrm{Rp})\end{array}$ \\
\hline 2016 & 150.000 & 450.000 & 600.000 \\
2017 & 150.000 & 450.000 & 600.000 \\
2018 & 150.000 & 450.000 & 600.000
\end{tabular}

Sumber: data primer diolah, 2019

Berdasarkan Tabel 4, besarnya biaya pesan sebesar Rp600.000,00 per tahun. Hal ini disebabkan tidak adanya diskon atau pengurangan harga pada pembelian bahan baku. Tetapi di akhir tahun suplier memberikan bingkisan yang bermacammacam seperti alat rumah tangga dan sembako sehingga dapat disimpulkan bahwa biaya pesan yang dikeluarkan oleh 20 UKM produsen pia di Kampung Pia Gempol konstan.

\section{Biaya Simpan}

Biaya penyimpanan untuk analisis perhitungan menggunakan bentuk persentase nilai dari persediaan. Adapun besarnya nilai persediaan yang ditetapkan perusahaan dalam penyimpanan bahan baku yaitu sebesar $1 \%$ dari nilai persediaan. Data biaya penyimpanan seperti pada Tabel 5 .

Tabel 5. Biaya Simpan

\begin{tabular}{ccccc}
\hline \multirow{2}{*}{ Tahun } & \multicolumn{2}{c}{ Tepung terigu } & \multicolumn{2}{c}{ Kacang Hijau Kupas } \\
\cline { 2 - 5 } & $\begin{array}{c}\text { Harga beli } \\
(\mathrm{Rp})\end{array}$ & $\begin{array}{c}1 \% \text { harga } \\
\text { beli }\end{array}$ & $\begin{array}{c}\text { Harga beli } \\
(\mathrm{Rp})\end{array}$ & $\begin{array}{c}1 \% \text { harga } \\
\text { beli }\end{array}$ \\
$(\mathrm{Kg})$ & $(\mathrm{Rp})$ & $(\mathrm{Kg})$ & $(\mathrm{Rp})$ \\
\hline 2016 & 7000 & 70 & 21000 & 210 \\
2017 & 7300 & 73 & 23000 & 230 \\
2018 & 7300 & 73 & 23000 & 230
\end{tabular}

Sumber: data primer diolah, 2019

Biaya penyimpanan yang dikeluarkan untuk bahan baku tepung terigu besarnya sama untuk dua tahun terakhir yaitu sebesar Rp26.280,00 per tahun (Rp73,00 x 360 hari) dan untuk kacang hijau kupas sebesar Rp82.800,00 per tahun (Rp230,00 x 360 hari) disebabkan harga beli yang ditetapkan oleh suplier masih belum mengalami kenaikan dan diperkirakan kenaikan harga akan terjadi pada akhir tahun sebesar 2\%-4\% dari harga beli.

\section{Pembelian dan Penggunaan Bahan Baku Tepung Terigu}

Total pembelian bahan baku tepung terigu yang dilakukan oleh pelaku UKM pia dengan klasifikasi $\geq 3.000 \mathrm{~kg}$ di tahun 2016 sebesar $61.810 \mathrm{~kg}$, tahun 2017 sebesar $62.650 \mathrm{~kg}$, dan tahun 2018 sebesar 64.100 $\mathrm{kg}$. Sedangkan klasifikasi pembelian antara 2.000-2.999 kg di tahun 2016 sebesar 7.221 $\mathrm{kg}$, tahun 2017 sebesar $7.365 \mathrm{~kg}$, dan tahun 2018 sebesar $7.460 \mathrm{~kg}$. Untuk klasifikasi 
bahan baku antara $1.000-1.999 \mathrm{~kg}$ di tahun 2016 sebesar $11.420 \mathrm{~kg}$, tahun 2017 sebesar $11.480 \mathrm{~kg}$, dan tahun 2018 sebesar 11.670 $\mathrm{kg}$.

Total penggunaan bahan baku tepung terigu yang dilakukan oleh pelaku UKM pia dengan klasifikasi $\geq 3.000 \mathrm{~kg}$ ditahun 2016 sebesar 61.805,5 kg, 2017 sebesar 62.646,5 $\mathrm{kg}$, dan 2018 sebesar 64.084,8 kg. Sedangkan klasifikasi pembelian antara 2.000-2.999 kg di tahun 2016 sebesar $7.220,2 \mathrm{~kg}$, tahun 2017 sebesar 7.360,3 kg, dan tahun 2018 sebesar $7.456,8 \mathrm{~kg}$. Untuk klasifikasi bahan baku antara 1.000-1.999 kg di tahun 2016 sebesar $11.415,7 \mathrm{~kg}$, tahun 2017 sebesar 11.460,4 dan tahun 2018 sebesar $11.668,8 \mathrm{~kg}$.

\section{Pembelian dan Penggunaan Bahan Baku Kacang Hijau Kupas}

Pembelian bahan baku kacang hijau kupas yang dilakukan oleh pelaku UKM pia dengan klasifikasi $\geq 3.000 \mathrm{~kg}$ di tahun 2016 sebesar $20.100 \mathrm{~kg}$, tahun 2017 sebesar $21.000 \mathrm{~kg}$, dan tahun 2018 sebesar 21.500 $\mathrm{kg}$. Sedangkan klasifikasi pembelian antara $2.000-2.999 \mathrm{~kg}$ di tahun 2016 sebesar 5.170 $\mathrm{kg}$, tahun 2017 sebesar $5.310 \mathrm{~kg}$, dan tahun 2018 sebesar $5.500 \mathrm{~kg}$. Klasifikasi bahan baku antara 1.000-1.999 kg di tahun 2016 sebesar $10.500 \mathrm{~kg}$, tahun 2017 sebesar 10.800 dan tahun 2018 sebesar $11.400 \mathrm{~kg}$. Untuk klasifikasi $<1.000 \mathrm{~kg}$ di tahun 2016 sebesar $5.680 \mathrm{~kg}$, tahun 2017 sebesar 5.900 $\mathrm{kg}$, dan tahun 2018 sebesar $6.200 \mathrm{~kg}$.

Total penggunaan bahan baku kacang hijau kupas yang dilakukan oleh pelaku UKM pia dengan klasifikasi $\geq 3.000 \mathrm{~kg}$ di tahun 2016 sebesar 20.073,4 kg, tahun 2017 sebesar 20.919,1 kg, dan tahun 2018 sebesar $21.465,6 \quad \mathrm{~kg}$. Sedangkan klasifikasi pembelian antara $2.000-2.999 \mathrm{~kg}$, di tahun 2016 sebesar $5.168,8 \mathrm{~kg}$, tahun 2017 sebesar $5.302,8 \mathrm{~kg}$, dan tahun 2018 sebesar 5.491,2 $\mathrm{kg}$. Untuk klasifikasi bahan baku antara $1.000-1.999 \mathrm{~kg}$ di tahun 2016 sebesar $10.495,4 \mathrm{~kg}$, tahun 2017 sebesar 10.781,5 kg, tahun 2018 sebesar $11.388 \mathrm{~kg}$. Untuk klasifikasi $<1.000 \mathrm{~kg}$ di tahun 2016 sebesar
5.653,5 klogram, tahun 2017 sebesar 5.894,8

$\mathrm{kg}$ dan tahun 2018 sebesar $6.177,6 \mathrm{~kg}$.

\section{Penentuan Kebutuhan Bahan Baku Periode yang Akan Datang \\ Hasil perhitungan dengan model} Moving Average terlihat bahwa penggunaan bahan baku tepung terigu pada beberapa UKM yang tergabung dalam Koperasi WASUKA: 1) Klasifikasi penggunaan bahan baku lebih dari $3.000 \mathrm{~kg}$ sebesar 62.845,6 $\mathrm{kg}$; 2) Klasifikasi penggunaan bahan baku antara 2.000-2.999 kg sebesar 7.345,8 kg; dan 3) Klasifikasi penggunaan bahan baku antara 1.000-1.999 kg per tahun sebesar $11.515 \mathrm{~kg}$. Sedangkan hasil perhitungan untuk bahan baku kacang hijau kupas sebagai berikut: 1) Klasifikasi penggunaan bahan baku lebih dari $3.000 \mathrm{~kg}$ sebesar $20.819,4 \mathrm{~kg}$; 2) Klasifikasi penggunaan bahan baku antara 2.000-2.999 kg sebesar $5.320 \mathrm{~kg}$; 3) Klasifikasi penggunaan bahan baku antara 1.000-1.999 kg per tahun sebesar 10.888,3 kg; dan 4) Klasifikasi penggunaan bahan baku $<1.000 \mathrm{~kg}$ per tahun sebesar $5.908 \mathrm{~kg}$.

\section{Pembelian Paling Ekonomis}

Penyediaan bahan baku tepung terigu yang paling ekonomis menurut metode EOQ adalah: 1) Klasifikasi pembelian bahan baku $\geq 3.000$ per tahun adalah sebesar $1.694 \mathrm{~kg}$ dengan frekuensi pembelian sebesar 37 kali dalam setahun sehingga pembelian opimalnya sebesar $62.678 \mathrm{~kg}$ dengan tenggang waktu 8 hari; 2) Klasifikasi pembelian bahan baku antara $2.000-2.999 \mathrm{~kg}$ per tahun sebesar 579,2 kg dengan 12,5 kali frekuensi pembelian sehingga optimalnya sebesar $7.240 \mathrm{~kg}$ dalam tempo 25 hari; dan 3) Klasifikasi pembelian bahan baku antara 1.000-1.999 kg per tahun sebesar $725 \mathrm{~kg}$ dengan frekuensi pembelian sebesar 15,5 kali sehingga pembelian optimalnya sebesar $11.237,5 \mathrm{~kg}$ dengan tenggang waktu 20 hari.

Sedangkan pembelian yang paling ekonomis untuk bahan baku kacang hijau kupas adalah: 1) Klasifikasi pembelian bahan bakunya $\geq 3.000 \mathrm{~kg}$ per tahun pembelian optimalnya sebesar 549,3 $\mathrm{kg}$ dengan 
frekuensi pembelian sebesar 37,5 kali sehingga pembelian optimalnya sebesar $20.598,8 \mathrm{~kg}$ dengan tenggang waktu antar pesanan selama 8 hari; 2) Klasifikasi pembelian bahan baku antara 2.000-2.999 kg per tahun pembelian ekonomisnya adalah $277,7 \mathrm{~kg}$ dengan frekuensi sebesar $19 \mathrm{kali}$ sehingga pembelian optimalnya sebesar $5.276,3 \mathrm{~kg}$ dengan tenggang waktu selama 16 hari; 3) Klasifikasi bahan baku antara 1.000-1.999 kg per tahun pembelian ekonomisnya sebesar 397,3 $\mathrm{kg}$ dengan frekuensi pembelian sebesar 27 kali dalam setahun sehingga pembelian optimalnya sebesar $10.727,1 \mathrm{~kg}$ dengan waktu tunggu antar pesanan 11 hari; dan 4) Klasifikasi pembelian bahan baku $<1.000 \mathrm{~kg}$ per tahun pembelian ekonomisnya sebesar 292,6 kg dengan frekuensi pembelian sebesar $20 \mathrm{kali}$ sehingga pembelian optimalnya sebesar $5.852 \mathrm{~kg}$ dengan waktu tunggu antar pesanan selama 15 hari.

\section{Persediaan Pengaman}

Jumlah persediaan yang dapat dicadangkan sebagai pengaman kelangsungan proses produksi dari resiko kehabisan bahan baku ( Stock Out ) untuk tepung terigu dapat diketahui sebagai berikut: 1) Persediaan pengaman sebesar $1.275 \mathrm{~kg}$ per tahun atau sebesar $34,5 \mathrm{~kg}$ setiap kali pesan untuk bahan baku tepung terigu pada klasifikasi pembelian bahan baku $\geq 3.000 \mathrm{~kg}$,; 2) Persediaan pengaman sebesar $114,4 \mathrm{~kg}$ atau $9 \mathrm{~kg}$ setiap kali pesan untuk pembelian bahan baku antara 2.000-2.999 $\mathrm{kg}$; dan 3) Persediaan pengaman sebesar $113,2 \mathrm{~kg}$ atau $7 \mathrm{~kg}$ setiap kali pesan untuk kualifikasi pembelian bahan baku antara 1.000-1.999 kg. Sedangkan persediaan pengaman untuk bahan baku kacang hijau kupas diperlukan: 1) Persediaan pengaman $285,3 \mathrm{~kg}$ per tahun atau sebesar 7,6 kg setiap kali pesan untuk bahan baku kacang hijau pada klasifikasi pembelian bahan baku $\geq$ $3.000 \mathrm{~kg}$; 2) Persediaan pengaman $131,5 \mathrm{~kg}$ atau 6,9 kg setiap kali pesan untuk pembelian bahan baku antara 2.000-2.999 $\mathrm{kg}$; 3) Persediaan pengaman $346,2 \mathrm{~kg}$ atau $12,8 \mathrm{~kg}$ setiap kali pesan untuk klasifikasi pembelian bahan baku antara 1.000-1.999 $\mathrm{kg}$; dan 4) Persediaan pengaman 411, $7 \mathrm{~kg}$ atau 20,6 $\mathrm{kg}$ setiap kali pesan untuk klasifikasi bahan baku $<1.000 \mathrm{~kg}$.

\section{Titik Pemesanan Ulang}

Titik pemesanan ulang untuk tepung terigu dengan tenggang waktu (leadtime) selama 2 hari dan hari kerja 26 hari adalah sebagai berikut: 1) Klasifikasi pembelian bahan baku tepung terigu $\geq 3.000 \mathrm{~kg}$ adalah ketika persediaan di gudang sebesar 401,8 $\mathrm{kg}$; 2) Klasifikasi bahan baku antara 2.000$2.999 \mathrm{~kg}$ per tahun adalah ketika persediaan di gudang sebesar 46,4 kg; dan 3) Klasifikasi pembelian bahan baku antara 1.000-1.999 kg per tahun adalah ketika persediaan di gudang $72 \mathrm{~kg}$.

Sedangkan titik pemesanan ulang untuk kacang hijau kupas adalah sebagai berikut: 1) Klasifikasi bahan baku kacang hijau kupas $\geq 3.000 \mathrm{~kg}$ adalah ketika persediaan di gudang $132 \mathrm{~kg}$; 2) Klasifikasi bahan baku antara 2.000-2.999 kg per tahun adalah ketika persediaan di gudang sebesar $34 \mathrm{~kg}$; 3) Klasifikasi pembelian bahan baku antara 1.000-1.999 kg per tahun adalah ketika persediaan di gudang sebesar $68,8 \mathrm{~kg}$; dan 4) klasifikasi bahan baku $<1.000 \mathrm{~kg}$ per tahun adalah ketika persediaan di gudang $37,6 \mathrm{~kg}$.

Adapun data total biaya persediaan disajikan pada Tabel 6.

Tabel 6. Total Biaya Persediaan

\begin{tabular}{|c|c|c|c|c|c|}
\hline & & Penggun & & & \\
\hline $\begin{array}{c}\text { Jenis } \\
\text { Bahan } \\
\text { Baku }\end{array}$ & $\begin{array}{c}\text { Klasifikasi } \\
\text { Pembelian } \\
\text { per Tahun } \\
\quad(\mathrm{Kg})\end{array}$ & $\begin{array}{c}\text { aan } \\
\text { Bahan } \\
\text { Baku } \\
\text { per } \\
\text { Tahun } \\
\text { (D) } \\
\text { ( Kg) }\end{array}$ & $\begin{array}{c}\text { Pembelia } \\
\text { n Paling } \\
\text { ekonomis } \\
(\mathrm{Q}) \\
(\mathrm{Kg})\end{array}$ & $\begin{array}{c}\text { Biaya } \\
\text { Pesan } \\
(\mathrm{S}) \\
(\mathrm{Rp})\end{array}$ & $\begin{array}{c}\text { Biaya } \\
\text { Simpan } \\
(\mathrm{H}) \\
(\mathrm{Rp})\end{array}$ \\
\hline \multirow{3}{*}{$\begin{array}{l}\text { Tepung } \\
\text { Terigu }\end{array}$} & $\geq 3.000$ & 62.678 & 1.694 & 50.000 & 73 \\
\hline & $\begin{array}{l}2.000- \\
2.999\end{array}$ & 7.240 & 579,2 & 50.000 & 73 \\
\hline & $\begin{array}{l}1.000- \\
1.999\end{array}$ & $11.237,5$ & 725 & 50.000 & 73 \\
\hline \multirow{4}{*}{$\begin{array}{l}\text { Kacang } \\
\text { Hijau } \\
\text { Kupas }\end{array}$} & $\geq 3.000$ & $20.598,8$ & 549,3 & 50.000 & 230 \\
\hline & $\begin{array}{l}2.000- \\
2.999\end{array}$ & $5.276,3$ & 277,7 & 50.000 & 230 \\
\hline & $\begin{array}{l}1.000- \\
1.999\end{array}$ & $10.727,1$ & 397,3 & 50.000 & 230 \\
\hline & $<1.000$ & 5.852 & 292,6 & 50.000 & 230 \\
\hline
\end{tabular}

Sumber: data primer diolah, 2019 
Total biaya persediaan bahan baku tepung terigu yang harus dikeluarkan oleh pelaku UKM pia menurut perhitungan yaitu: 1) Klasifikasi pembelian bahan baku tepung terigu $\geq 3.000 \mathrm{~kg}$ per tahun sebesar Rp1.911.831,00 per tahun; 2) Klasifikasi bahan baku antara 2.000-2.999 kg per tahun sebesar Rp646.140,00; dan 3) Klasifikasi bahan baku antara 1.000- $1.999 \mathrm{~kg}$ per tahun. sebesar Rp801.462,00.

Total biaya persediaan yang harus dikeluarkan pada pembelian bahan baku kacang hijau kupas adalah: 1) Pembelian bahan baku Rp1.938.173,00 untuk klasifikasi pembelian bahan baku $\geq 3.000 \mathrm{~kg}$ per tahun; 2) Pembelian Rp981.935,00 untuk klasifikasi bahan baku antara 2.000-2.999 kg per tahun; 3) Pembelian sebesar Rp1.395.689,00 untuk klasifikasi bahan baku antara 1.000-1.999 kg per tahun; dan 4) Pembelian sebesar Rp1.033.649,00 untuk pembelian bahan baku $<1.000 \mathrm{~kg}$ per tahun.

\section{Efisiensi}

Efisiensi persediaan dapat diketahui dengan cara menghitung selisih antara anggaran dengan realisasinya. Data-data yang diperlukan dalam perhitungan efisiensi total biaya persediaan bahan baku seperti pada Tabel 7.

Tabel 7. Perhitungan Efisiensi Total Biaya Persediaan

\begin{tabular}{|c|c|c|c|c|c|}
\hline $\begin{array}{c}\text { Bahan } \\
\text { Baku }\end{array}$ & $\begin{array}{l}\text { Klasifikas } \\
\text { i Bahan } \\
\text { baku }(\mathrm{Kg})\end{array}$ & Metode & $\begin{array}{c}\text { Keb BB } \\
(\mathrm{Kg})\end{array}$ & $\begin{array}{c}\text { Harga } \\
\text { per Kg } \\
(\mathrm{Rp})\end{array}$ & $\begin{array}{l}\text { Total Biaya } \\
\text { (Rp) }\end{array}$ \\
\hline \multirow{7}{*}{$\begin{array}{l}\text { Tepung } \\
\text { Terigu }\end{array}$} & \multirow[t]{2}{*}{$\geq 3.000$} & $\begin{array}{l}\text { Kebijakan } \\
\text { Perusahaan }\end{array}$ & $62.845,6$ & 7.300 & 458.772 .880 \\
\hline & & Metode $E O Q$ & 62.678 & 7.300 & 457.549 .400 \\
\hline & \multirow{3}{*}{$\begin{array}{l}2.000- \\
2.999\end{array}$} & $\begin{array}{l}\text { Kebijakan } \\
\text { Perusahaan }\end{array}$ & $7.345,8$ & 7.300 & 53.624 .340 \\
\hline & & Metode $E O Q$ & 7.240 & 7.300 & 52.852 .000 \\
\hline & & Kebijakan & 11.515 & 7.300 & 84.059 .500 \\
\hline & \multirow{2}{*}{$\begin{array}{c}1.000- \\
1.999\end{array}$} & Perusahaan & & & \\
\hline & & Metode $E O Q$ & $11.237,5$ & 7.300 & 82.033 .750 \\
\hline \multirow{11}{*}{$\begin{array}{l}\text { Kacang } \\
\text { Hijau } \\
\text { Kupas }\end{array}$} & \multirow{3}{*}{$\geq 3.000$} & Kebijakan & $20.819,4$ & 23.000 & 478.846 .200 \\
\hline & & Perusahaan & & & \\
\hline & & Metode $E O Q$ & $20.598,8$ & 23.000 & 473.772 .400 \\
\hline & \multirow{4}{*}{$\begin{array}{l}2.000- \\
2.999\end{array}$} & Kebijakan & 5.320 & 23.000 & 122.360 .000 \\
\hline & & Perusahaan & & & \\
\hline & & Metode $E O Q$ & $5.276,3$ & 23.000 & 121.354 .900 \\
\hline & & Kebijakan & $10.888,3$ & 23.000 & 250.430 .900 \\
\hline & \multirow{2}{*}{$\begin{array}{c}1.000- \\
1.999\end{array}$} & Perusahaan & & & \\
\hline & & Metode $E O Q$ & $10.727,1$ & 23.000 & 246.723 .300 \\
\hline & \multirow[t]{2}{*}{$<1.000$} & $\begin{array}{l}\text { Kebijakan } \\
\text { Perusahaan }\end{array}$ & 5.908 & 23.000 & 135.884 .000 \\
\hline & & Metode $E O Q$ & 5.852 & 23.000 & 134.596 .000 \\
\hline
\end{tabular}

Sumber: data primer diolah penulis, 2019
Data kebutuhan bahan baku disajikan dalam bentuk diagram batang beserta teknis perhitungan efisiensinya. Diagram kebutuhan bahan baku klasifikasi $>3.000 \mathrm{~kg}$ seperti Gambar 1.

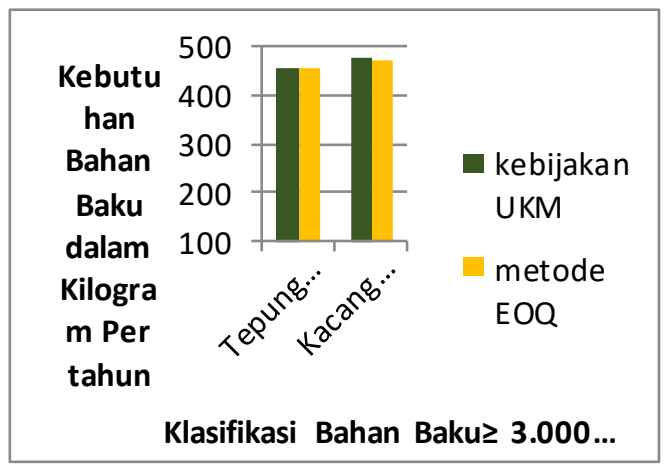

Gambar 1. Diagram Kebutuhan Bahan Baku (Klasifikasi $\geq 3.000 \mathrm{Kg}$ )

Sumber: data primer diolah, 2019

\section{Efisiensi Tepung Terigu}

$\frac{\text { anggaran sebelum - anggaran sesudah }}{\text { anggaran sebelum }} \times 100 \%=$
$\frac{458.772 .880-457.549 .400}{457.549 .400} \times 100 \%=$
$0,27 \%$

\section{Efisiensi Kacang Hijau Kupas:}

$$
\begin{aligned}
& \frac{\text { anggaran sebelum - anggaran sesudah }}{\text { anggaran sebelum }} \times 100 \% \\
& =\frac{478.846 .200-473.772 .400}{473.772 .400} \times 100 \%= \\
& 1,06 \%
\end{aligned}
$$

Berdasarkan hasil perhitungan diperoleh tingkat efisiensi berdasarkan metode EOQ untuk pembelian bahan baku tepung terigu klasifikasi $\geq 3.000 \mathrm{~kg}$ sebesar 0,27\%, Sedangkan untuk klasifikasi pembelian bahan baku kacang hijau kupas $\geq$ 3.000 sebesar $1,06 \%$. Dengan kata lain, para UKM yang tergabung dalam Koperasi Waru Sukses Berkarya dengan klasifikasi penggunaan bahan baku $\geq 3.000 \mathrm{~kg}$ apabila menggunakan metode EOQ akan menghemat biaya pembelian bahan baku tepung terigu sebesar 0,27\% atau sekitar Rp1.223.480,00 
dan kacang hijau kupas sebesar $1,06 \%$ atau Rp5.073.800,00 dibanding dengan metode yang selama ini mereka gunakan.

Diagram kebutuhan bahan baku dengan klasifikasi 2.000-2.999 Kgdisajikan pada Gambar 2.

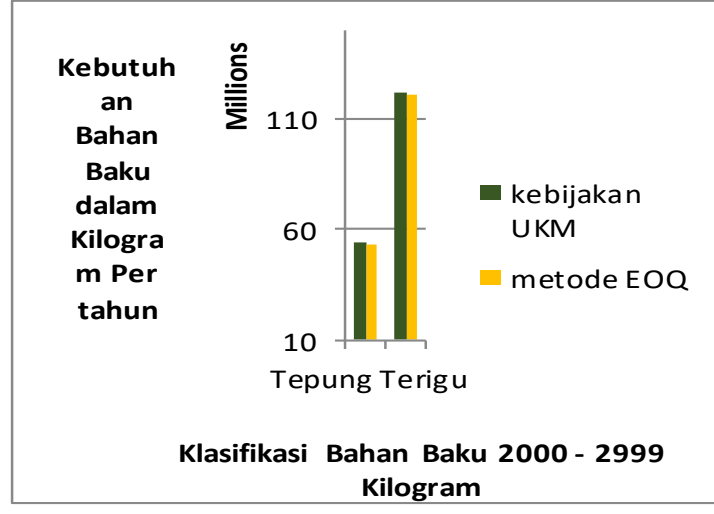

Gambar 2. Diagram Kebutuhan Bahan Baku (Klasifikasi $\geq 2.000-2.999 \mathrm{Kg}$ ) Sumber: data primer diolah, 2019

\section{Efisiensi Tepung Terigu}

$\frac{\text { anggaran sebelum - anggaran sesudah }}{\text { anggaran sebelum }} \times 100 \%=$ $\frac{53.624 .340-52.852 .000}{53.624 .340} \times 100 \%=1,44 \%$

\section{Efisiensi Kacang Hijau Kupas}

$$
\begin{aligned}
& \frac{\text { anggaran sebelum - anggaran sesudah }}{\text { anggaran sebelum }} \times 100 \%= \\
& \frac{122.360 .000-121.354 .900}{122.360 .000} \times 100 \%=0,82 \%
\end{aligned}
$$

Hasil perhitungan diperoleh bahwa efisiensi berdasarkan metode EOQ untuk pembelian bahan baku tepung terigu kualifikasi antara 2.000-2.999 kg sebesar $1,44 \%$. Sedangkan untuk kualifikasi pembelian bahan baku kacang hijau kupas antara 2.000-2.999 kg sebesar 0,82\%. Dengan kata lain, para UKM yang tergabung dalam Koperasi Waru Sukses Berkarya dengan kualifikasi penggunaan bahan baku 2.000-2.999 kg apabila menggunakan metode EOQ akan menghemat biaya pembelian bahan baku tepung terigu sebesar
1,44\% atau sekitar Rp772.340,00 dan kacang hijau kupas sebesar $0,82 \%$ atau Rp1.005.100,00 dibanding dengan metode yang selama ini mereka gunakan.

Diagram kebutuhan bahan baku klasifikasi 1.000-1.999 kg seperti pada Gambar 3.

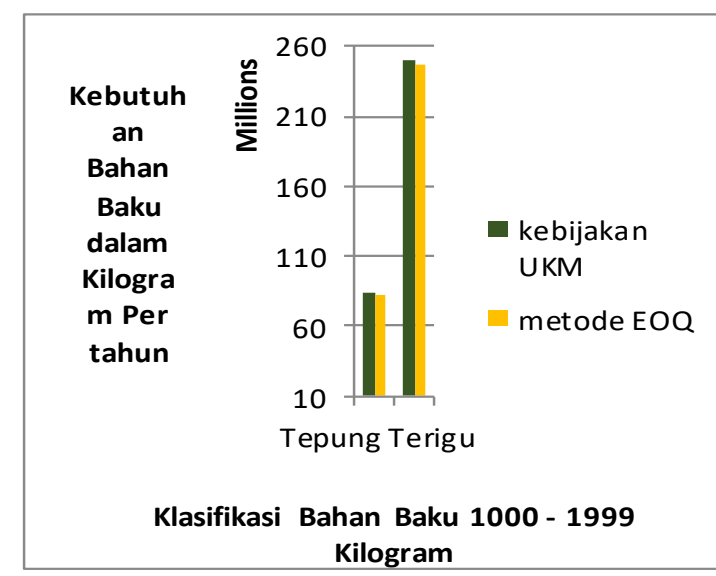

Gambar 3. Diagram Kebutuhan Bahan Baku (Klasifikasi 1.000-1.999 Kg)

Sumber: data primer diolah, 2019

\section{Efisiensi Tepung Terigu}

$\frac{\text { anggaran sebelum - anggaran sesudah }}{\text { anggaran sebelum }} \times 100 \%=$ $\frac{84.059 .500-82.033 .750}{84.059 .500} \times 100 \%=2,41 \%$

\section{Efisiensi Kacang Hijau Kupas}

$$
\begin{aligned}
& \frac{\text { anggaran sebelum - anggaran sesudah }}{\text { anggaran sebelum }} \times 100 \%= \\
& \frac{250.430 .900-246.723 .300}{250.430 .900} \times 100 \%=1,48 \%
\end{aligned}
$$

Hasil perhitungan diperoleh bahwa efisiensi berdasarkan metode EOQ untuk pembelian bahan baku tepung terigu klasifikasi antara 1.000-1.999 kg sebesar 2,41\%, Sedangkan untuk klasifikasi pembelian bahan baku kacang hijau kupas antara 1.000-1.999 kg sebesar 1,48\%. Dengan kata lain, para UKM yang tergabung dalam Koperasi Waru Sukses Berkarya dengan klasifikasi penggunaan bahan baku 1.000-1.999 kg apabila menggunakan 
metode EOQ akan menghemat biaya pembelian bahan baku tepung terigu sebesar 2,41\% atau sekitar Rp2.025.750,00 dan kacang hijau kupas sebesar $1,48 \%$ atau Rp3.707.600,00 dibanding dengan metode yang selama ini mereka gunakan.

Diagram kebutuhan bahan baku kacang hijau kupas dengan klasifikasi < $1.000 \mathrm{~kg}$ disajikan pada Gambar 4.

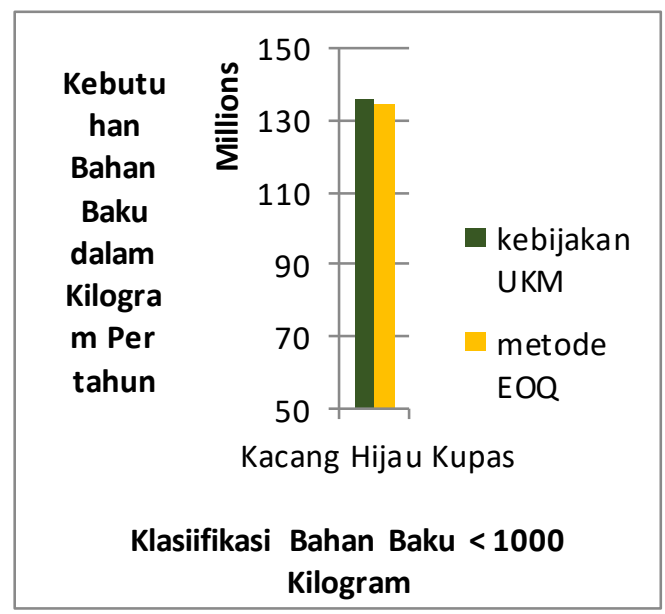

Gambar 4. Diagram Kebutuhan Bahan Baku Kacang Hijau Kupas (Klasifikasi $<1.000 \mathrm{Kg}$ ) Sumber: data primer diolah, 2019

\section{Efisiensi Kacang Hijau Kupas}

$$
\frac{\text { anggaran sebelum - anggaran sesudah }}{\text { anggaran sebelum }} \times 100 \%=
$$$$
\frac{135.884 .000-134.596 .000}{135.884 .000} \times 100 \%=0,95 \%
$$

Efisiensi berdasarkan metode EOQ untuk klasifikasi pembelian bahan baku kacang hijau $<1.000 \mathrm{~kg}$ adalah sebesar 0,95\%. Dengan kata lain, para UKM yang tergabung dalam Koperasi Waru Sukses Berkarya dengan klasifikasi penggunaan bahan baku $<1.000 \mathrm{~kg}$ apabila menggunakan metode EOQ akan menghemat biaya pembelian bahan baku kacang hijau kupas sebesar $0,95 \%$ atau Rp1.288.000,00 dibanding dengan metode yang selama ini mereka gunakan.

Setelah semua klasifikasi bahan baku baik tepung terigu maupun kacang hijau kupas telah diketahui tingkat efisiensinya, diharapkan para pelaku UKM menggunakan metode EOQ sebagai acuan untuk melakukan pembelian bahan baku sehingga para pelaku UKM bisa menekan biaya-biaya yang dikeluarkan dalam proses produksinya.

Berdasarkan hasil penelitian dan hasil perhitungan yang dilakukan, maka diketahui pemakaian bahan baku tepung terigu dan kacang hijau kupas pada para pelaku usaha pia yang berada di Kampung Pia Gempol masih berfluktuasi. Dengan demikian penting bagi UKM untuk melaksanakan suatu metode pembelian persediaan yang lebih efisien, sehingga biaya yang dikeluarkan untuk persediaan dapat ditekan seminimal mungkin.

Metode pembelian yang biasa dikenal dengan Economic Order Quantity (EOQ) dapat digunakan untuk mengatasi pemakaian yang berfluktuasi tersebut. Dalam perhitungannya, metode ini dipertimbangkan beberapa hal, antara lain jumlah kebutuhan bahan baku, biaya pemesanan, dan biaya penyimpanan. Tetapi perlu diingat juga bahwa metode pembelian persediaan dengan menggunakan metode EOQ juga memiliki banyak keterbatasan dan kondisi-kondisi yang harus dipenuhi, misalnya tentang perubahan harga yang kemungkinan terjadi, maka hendaknya perusahaan juga memperhatikan faktor perubahan harga dalam menentukan pembelian persediaan bahan baku. Selain itu, dalam penggunaan metode EOQ terdapat beberapa asumsi yang harus dipenuhi, antara lain permintaan akan produk, harga per unit produk, biaya penyimpanan produk per unit per tahun, biaya pemesanan, waktu antara pemesanan dilakukan sampai dengan barang diterima, dan ketersediaan bahan baku di pasar.

Pembelian bahan baku tepung terigu dan kacang hijau kupas yang dilakukan oleh beberapa pelaku UKM pia di Kampung Pia Gempol apabila menggunakan metode EOQ dengan beberapa klasifikasi yang telah ditentukan dinilai cukup efisien meskipun dengan persentase yang tidak terlalu besar. Hal ini dikarenakan frekuensi pembelian yang dilakukan cukup sering sehingga biaya pesan dan biaya simpan juga relatif banyak. Selain itu, perolehan bahan baku yang 
dibutuhkan oleh beberapa UKM yang tergabung dalam Koperasi WASUKA dinilai cukup mudah didapatkan mengingat keberadaan suplier bahan baku tersebut dekat dengan lokasi usaha. Namun apabila dibandingkan dengan kebijakan yang umumnya dilakukan oleh pelaku usaha pia yang melakukan pembelian bahan baku tanpa terjadwal (pembelian dilakukan apabila bahan baku habis) biaya yang dikeluarkan lebih besar. Dalam hal ini disarankan kepada para pelaku usaha pia untuk menggunakan metode EOQ sehingga dana yang dikeluarkan untuk keperluan pembelian bisa dialokasikan untuk kebutuhan lainnya (Alamsyah et al., 2013). Meskipun terdapat efisiensi dalam pembelian bahan baku tidak akan berpengaruh terhadap proses produksi karena tersedianya persediaan pengaman (Safety Stocks ).

Besarnya persediaan pengaman (Safety Stocks) dipengaruhi oleh besarnya penggunaan bahan baku setiap bulan. Besarnya penggunaan bahan baku tepung terigu dan kacang hijau kupas dalam setahun menentukan besarnya standar deviasi, hal ini memperkuat hasil penelitian yang dilakukan oleh (Rakian et al, 2015). Sartono (2009) menyatakan bahwa persediaan pengaman (Safety Stocks) sangat penting dilakukan mengingat kebutuhan bahan baku yang dibutuhkan para pelaku UKM tersebut berfluktuasi. Persediaan pengaman juga berfungsi untuk menanggulangi terjadinya keterlambatan datangnya bahan bahan baku. Dengan adanya persediaan pengaman, diharapkan proses produksi tidak terganggu oleh adanya ketidakpastian bahan baku. Hal ini juga dipaparkan oleh (Tuerah, 2014).

Penentuan titik pemesanan ulang (Reorder Point), tidak ada kebijakan yang dikeluarkan oleh tiap-tiap pelaku usaha pia. Pemesanan akan kembali dilakukan apabila persediaan digudang hampir habis sehingga dalam hal ini penulis meramalkan titik pemesanan ulang yang harus digunakan oleh pelaku usaha pia untuk menghemat biayabiaya yang mungkin akan timbul dikemudian hari. Hal ini memperjelas hasil penelitian Darmawan et al. (2015) yang menyatakan bahwa titik pemesanan ulang perlu ditetapkan agar pembelian bahan baku yang sudah ditetapkan melalui metode EOQ tidak menganggu kelancaran proses produksi. Dengan menggunakan metode EOQ, total biaya persediaan bahan baku yang dikeluarkan dapat efisien. Hal ini dikarenakan kuantitas pembelian bahan baku lebih sedikit sehingga total biaya persediaan juga berkurang dibanding apabila para pelaku UKM yang melakukan pembelian tidak terjadwal. Hasil penelitian ini memperkuat hasil penelitian yang dilakukan oleh Prihasdi dan Rahardjo (2012) dimana metode EOQ berpengaruh positif terhadap total biaya persediaan bahan baku sehingga terjadi efisiensi biaya yang berujung dengan meningkatnya keuntungan yang diperoleh para pelaku usaha.

\section{Kesimpulan}

Hasil penelitian dapat disimpulkan bahwa pengawasan dan pengendalian bahan baku perlu di tingkatkan oleh para UKM Pia yang tergabung dalam koperasi Waru Sukses Berkarya secara berkesinambungan salah satunya dengan melakukan perencanaan pembelian bahan baku secara mendetail, menentukan besarnya persediaan pengaman (Safety Stocks) dan titik pemesanan ulang (Reorder Point) sehingga pengeluaran akibat keterlambatan atau penumpukan bahan baku dapat diminimalisir. Disamping itu, pengadministrasian pada tiap-tiap UKM perlu ditingkatkan mengingat data-data penting sangat diperlukan guna mengetahui sejauh mana para UKM yang tergabung dalam Koperasi Waru Sukses Berkarya berkembang dari tahun ke tahun.

\section{DAFTAR PUSTAKA}

Alamsyah, I., Prihatini, A., \& Wijayanto, A. (2013). Analisis Pengendalian Persediaan Bahan Baku Tembakau Dengan Menggunakan Metode EOQ (Economical Order Quantity) Guna Mencapai Efisiensi Total Biaya Persediaan Bahan Baku Pada PR. Gambang Sutra Kudus. Jurnal Ilmu Administrasi Bisnis. 
Darmawan, G. A., Cipta, W., \& Yulianthini, N. N. (2015). Penerapan Economic Order Quantity (EOQ) Dalam Pengelolaan Persediaan Bahan Baku Tepung pada Usaha Pia Ariawan di Desa Banyuning Tahun 2013. EJounal Bisma Universitas Pendidikan Ganesha.

Heizer, J. \& B. R. (2016). Manajemen Operasi Edisi Ketujuh. Jakarta: Salemba Empat

Lovelock, C., \& Wirtz, J. (2014). Services Marketing: People, Technology, Strategy. In Pearson. Https://Doi.Org/10.1044/10590889(2011/10-0028)

Sartono, A (2009). Manajemen Keuangan Teori dan Aplikasi. Yogyakarta: $\mathrm{BPFE}$

Sugiyono,P (2011). Metode Penelitian Kuantitatif, Kualitatif dan R \& D, Bandung: Alfabeta

Prihasdi, R. D., \& Rahardjo, S. N. (2012). Efisiensi Metode Economical Order Quantity (EOQ) dalam Pengambilan Keputusan Pembelian Bahan Baku dan Pengaruhnya terhadap Total Biaya Pembelian Pada PT Amitex (Amanah Mitra Industri) Buaran Kabupaten Pekalongan. Diponegoro Journal of Accounting, 1(1), 1-12.

Rakian, A., Hamid, L., \& Daulay, I. (2015). Analisis Pengendalian Persediaan Bahan Baku Tepung Terigu Menggunakan Metode EOQ Pada Pabrik Mie Musbar Pekanbaru. Jurnal Online Mahasiswa Fakultas Ekonomi Universitas Riau.

Tuerah, M. (2014). Analisis Pengendalian Persediaan Bahan Baku Ikan Tuna Pada Cv. Golden Kk. Jurnal Riset Ekonomi, Manajemen, Bisnis dan Akuntansi. 